\title{
A PRODUÇÃO DO CONHECIMENTO DO PPGEF/UFPEL SOBRE A REALIDADE DO TRABALHO DOCENTE NAS ESCOLAS PÚBLICAS DE PELOTAS/RS/BRASIL
}

\author{
Ivan Bremm De Oliveira \\ Universidade Federal de Pelotas, Pelotas, Rio Grande do Sul, Brasil \\ Giovanni Felipe Ernest Frizzo \\ Universidade Federal de Pelotas, Pelotas, Rio Grande do Sul, Brasil
}

\begin{abstract}
Resumo
O presente estudo objetivou sistematizar a produção do conhecimento desenvolvida no PPGEF/UFPel sobre o trabalho docente da Educação Física nas escolas públicas de Pelotas (RS). Após o levantamento da totalidade das produções, foram encontradas 14 dissertações. A partir da análise de conteúdo, estabelecemos quatro categorias: a) condições de trabalho e infraestrutura; b) formação inicial e continuada; c) políticas públicas; d) saúde docente. Os estudos apontaram precarização da educação pública e da carreira docente, exaustiva jornada de trabalho, baixa remuneração, carência de infraestrutura e materiais para as aulas de EF. Constataram-se ainda a fragilidade da formação inicial, a carência de ações de formação continuada, políticas públicas insuficientes e o esgotamento profissional.
\end{abstract}

Palavras-chave: Educação Física. Produção do Conhecimento. Educação Pública.

\section{Introdução}

O presente estudo tem como objetivo sistematizar a produção do conhecimento desenvolvida no Programa de Pós-Graduação em Educação Física da Universidade Federal de Pelotas (PPGEF/UFPel) sobre o trabalho docente da Educação Física (EF) nas escolas públicas de Pelotas (RS). Tal estudo é parte das pesquisas desenvolvidas pelo projeto intitulado Organização do Trabalho Pedagógico da Educação Física, desenvolvido na Escola Superior de Educação Física da UFPel. Este estudo se justifica pela necessidade de compreendermos os limites e os desafios com os quais o professorado da EF se depara no desenvolvimento de seu trabalho nas redes públicas de ensino e suas constatações permitem apontar elementos que subsidiem alternativas pedagógicas e mobilizações reivindicativas junto ao poder público com vistas à melhoria da qualidade da educação pública, especialmente no que tange à EF.

A temática do trabalho docente tem sido tratada com profundidade no último período em vista das mudanças no mundo do trabalho em geral, que têm impactado o trabalho docente. Em recente livro publicado, Souza, Ribas e Calheiros $(2015$, p. 15) apontam que, diante das mudanças que ocorrem no mundo do trabalho, "a área da Educação Física deve manter-se em alerta crítico, no sentido de apropriar-se dos aspectos sociais em que se encontram atrela- 
das tais mudanças, pois estas refletem diretamente na organização do trabalho pedagógico e, consequentemente, na práxis pedagógica".

Neste cenário de mudanças do mundo do trabalho, são desenvolvidas reformas educativas que modificam a estrutura da organização escolar e da carreira docente e que trazem consequências para as condições de trabalho do professorado de EF: "trata-se de condições estruturais que pautam a escola e o trabalho de seus professores no marco de uma sociedade capitalista, ocasionando fenômenos visíveis como a intensificação do trabalho e o isolamento dos trabalhadores" (MOLINA NETO; WITTIZORECKI, 2005, p. 63).

Tais questões estruturais decorrem da crescente precarização das escolas públicas. Filippini e Frizzo (2013), ao estudarem uma rede pública de ensino do Rio Grande do Sul, concluem que há uma precária infraestrutura nas escolas para as aulas de EF, carência de materiais didáticos, intensificação do trabalho docente decorrente da baixa remuneração e da ampliação da jornada, falta de incentivo à formação continuada e limitação do acesso ao conhecimento por parte dos estudantes.

Esse processo de intensificação do trabalho tem como um dos seus desdobramentos para o professorado o adoecimento docente. A Síndrome do Esgotamento Profissional (SANTINI, 2004), ou a Síndrome de Burnout (SINOTT et al., 2014), é cada vez mais constante na vida do professorado em decorrência das condições de trabalho e estudo, com as quais convivem diariamente nas escolas. As conclusões desses estudos apontam altos índices de exaustão emocional decorrente do trabalho e índices negativos de realização profissional, em que se ressaltam "a importância do fomento e do desenvolvimento de políticas públicas que favoreçam o reconhecimento e a valorização da profissão docente. O cuidado com a saúde do professor é uma emergência" (SINOTT et al., 2014, p. 535).

No que tange ao território delimitado para esta investigação - a rede pública de ensino de Pelotas (RS) -, é importante destacar que, em relação às condições de trabalho, tanto o professorado da rede estadual quanto da rede municipal não tem respeitada a Lei $11.738 / 2008$, que institui o piso salarial profissional nacional para os profissionais do magistério público da educação básica. Portanto, seus vencimentos estão abaixo do valor mínimo estipulado em lei. Ao mesmo tempo em que este é um elemento significativo no que diz respeito à precarização do trabalho docente, sua intensificação também decorre do fato de que as políticas educativas municipais e estaduais balizadas pelos índices e indicadores de avaliação de desempenho, com ênfase nos resultados, na produtividade e na responsabilização, influenciam sobremaneira as condições de trabalho. Ivo e Hypólito (2015, p. 365) alertam que essa "política orientada estritamente pelos índices e indicadores de qualidade, que regula o trabalho docente a partir do desempenho dos alunos, parece-nos estar longe de uma política realmente preocupada com a qualidade da Educação".

Com base nessas demandas decorrentes das mudanças no mundo do trabalho e da situação encontrada na educação pública em geral, buscamos sistematizar os elementos que têm sido apontados pela produção do conhecimento acerca da realidade do trabalho docente da EF na rede pública de Pelotas (RS), a partir das dissertações defendidas no PPGEF/UFPel, que permitem estabelecer um panorama da temática aprofundado através dos trabalhos de campo realizados por tais estudos.

\section{Organização metodológica do estudo}

O PPGEF/UFPel foi criado no ano de 2006, e a primeira turma do curso de mestrado em EF teve início em 2007. Desde então, em todos os anos houve seleção de novas turmas, sendo que no ano de 2014 ocorreu a primeira seleção para o curso de doutorado. Embora nesse período tenham ocorrido modificações em relação às áreas de concentração e linhas de pesquisa, é possível identificar a divisão entre as Ciências da Saúde e as Ciências Soci- 
ais/Humanas no oferecimento de vagas, disciplinas e distribuição dos docentes por linha de pesquisa desde o início do programa.

Atualmente, o PPGEF é dividido em duas áreas de concentração: a) Biodinâmica do Movimento Humano (BMH), cujas linhas de pesquisa são: Epidemiologia da Atividade Física e Desempenho e Metabolismo Humano; b) Movimento Humano, Educação e Sociedade (MHES), cujas linhas são: Comportamento Motor, Formação Profissional e Prática Pedagógica; Estudos Socioculturais do Esporte e da Saúde. Apesar das diferentes constituições de áreas e linhas, ao fazermos a compilação de todas as dissertações defendidas no período de 2008 a 2014 (período que corresponde à totalidade da produção do PPGEF), temos a seguinte configuração:

Quadro 1 - Dados sobre a produção do PPGEF por área de concentração

\begin{tabular}{|c|c|c|c|}
\hline ANO & $\begin{array}{c}\text { Biodinâmica do Mo- } \\
\text { vimento Humano }\end{array}$ & $\begin{array}{c}\text { Movimento Humano, } \\
\text { Educação e Sociedade }\end{array}$ & TOTAL \\
\hline 2008 & 2 & 0 & 2 \\
\hline 2009 & 3 & 10 & 13 \\
\hline 2010 & 7 & 15 & 22 \\
\hline 2011 & 7 & 10 & 17 \\
\hline 2012 & 14 & 19 & 33 \\
\hline 2013 & 13 & 16 & 29 \\
\hline 2014 & 14 & 14 & 28 \\
\hline TOTAL & $\mathbf{6 0}$ & $\mathbf{8 4}$ & $\mathbf{1 4 4}$ \\
\hline
\end{tabular}

Fonte: Secretaria do PPGEF.

Diferente de outras pesquisas acerca dos programas de pós-graduação em EF (FRIZZO, 2010; MOLINA NETO, 1999; JOB, 2006), o quadro sistematizado apresenta uma produção da área das Ciências Sociais e Humanas mais elevada do que da área das Ciências da Saúde. Da totalidade de dissertações apresentadas, aproximadamente 58\% das produções são da área de concentração MHES e $42 \%$ da área de concentração BMH. Cabe ressaltar que, no PPGEF/UFPel, a linha de pesquisa de Comportamento Motor faz parte da área MHES, porém, pela caracterização das pesquisas nessa área do conhecimento e pelos seus fundamentos técnico-científicos em outros programas de pós-graduação, essa linha faz parte da área das Ciências da Saúde. Isso pode ser um dos fatores que apontam que a maioria das dissertações são das Ciências Sociais e Humanas, diferente dos resultados de pesquisas sobre outros programas de pós-graduação em EF.

Após este levantamento inicial da totalidade das dissertações defendidas e a sua área de concentração correspondente, identificamos a quantidade de produções que tinham como temática de estudo a escola básica: foram encontradas 52 dissertações, correspondendo a $36,1 \%$ do total de 144 dissertações. $\mathrm{O}$ acesso à totalidade das dissertações do programa se deu através do Repositório Institucional da UFPel - Guaiaca, do site institucional do programa e da Secretaria do PPGEF. Ao analisarmos essas 52 produções, averiguamos que a temática do trabalho docente da EF na rede pública concentra-se nas produções da área de concentração MHES. Portanto, para a análise dessa temática, selecionamos somente as produções oriundas dessa área, resultando em 36 dissertações. No mesmo sentido, as dissertações que têm como 
linha de pesquisa o Comportamento Motor, ainda que componentes da MHES, foram retiradas do montante analisado, pelo fato de tratarem de intervenções pedagógicas ou aplicação de testes motores para a avaliação de valências físicas. Sendo assim, elas não se enquadram na temática central deste estudo.

Dessa forma, restaram 21 dissertações que tratam do trabalho docente na rede pública de ensino. Como o artigo ora apresentado busca compreender a realidade do trabalho docente na rede pública de Pelotas, eliminamos da análise as dissertações cuja investigação foi realizada em outras redes de ensino (privada ou em outros municípios). Por conseguinte, o montante de dissertações que foram analisadas, tendo compilados os seus resultados, é de 14 produções, que sistematizamos na forma de categorias que expressam os elementos centrais da produção do conhecimento do PPGEF/UFPel acerca do trabalho docente da EF na rede pública de Pelotas.

O processo de categorização foi estabelecido a partir da análise de conteúdo proposta por Bardin (2009), na qual o primeiro momento de pré-análise envolveu a leitura de cada uma das dissertações que foram definidas para a investigação, destacando os elementos centrais referentes ao objeto desta pesquisa. Após a apropriação do conteúdo da totalidade das produções, o segundo momento envolveu a exploração deste material, buscando estabelecer conexões entre os elementos destacados, identificando aproximações e distanciamentos que possibilitariam definir categorias empíricas; o terceiro momento envolveu a sistematização dos elementos na forma de categorias a partir de inferência e interpretação dos elementos destacados nas fases anteriores. A análise das 14 dissertações produzidas no PPGEF/UFPel que, de alguma forma, abordam o trabalho docente da EF na rede pública de ensino em Pelotas (RS) permitiu sistematizarmos em quatro categorias principais os elementos apontados nas produções acadêmicas, quais sejam: a) condições de trabalho e infraestrutura; b) formação inicial e continuada; c) políticas públicas; d) saúde docente.

\section{O trabalho docente nas escolas públicas de Pelotas}

O primeiro aspecto a destacar das produções analisadas diz respeito à caracterização geral das pesquisas elaboradas. Em relação ao nível teórico-epistemológico, duas sinalizações são bastante evidentes nas produções: em que pese o estabelecimento de posturas críticas, a maior parte das investigações não apresenta consistência suficientemente elaborada no referencial teórico acerca da abordagem científica que fundamentou a realização das pesquisas. Identificamos que a utilização dos autores de referência não estabelece um lastro epistemológico definido, apresentando variações epistemológicas de enfoques fenomenológicos, estruturalistas, teorias críticas da Escola de Frankfurt e pós-estruturalistas (dentre outros) em uma mesma investigação. Essa característica demarca um fenômeno expressivo das produções acadêmicas na atualidade: o ecletismo teórico ou multirreferencialidade.

Em menor número, algumas dissertações analisadas preocupam-se em definir as propriedades e os fundamentos do enfoque teórico-epistemológico que embasaram a investigação. Todas estas formulam o conhecimento científico através do materialismo históricodialético de base marxista.

Em relação às questões técnico-metodológicas, constatou-se que as pesquisas foram elaboradas com trabalho de campo empírico utilizando questionários, entrevistas, observação participante e análise de documentos, instrumentos tradicionais das pesquisas em Ciências Sociais e Humanas e que são fundamentais para a compreensão do fenômeno investigado e que articulam as formulações teóricas com a realidade concreta, enriquecendo os resultados na medida em que expressam, em maior ou menor grau, correspondência com o real objeto da pesquisa. Ainda, destaca-se o fato de que as investigações envolveram análises qualitativas e quantitativas, sem preponderância de um ou outro caráter de análise. Esse elemento é impor- 
tante na medida em que supera a forma dualista que apresenta antagonismo entre qualidade e quantidade nas pesquisas em Ciências Sociais e Humanas na EF.

\section{A) Condições de trabalho e infraestrutura}

A precarização das condições de trabalho nas redes públicas de ensino de Pelotas (RS) foi abordada por praticamente todas as dissertações analisadas. As investigações apontaram que os processos de precarização trazem consequências prejudiciais à qualidade do ensino da EF nas escolas. Em relação à jornada de trabalho docente, destacamos o fato de que a maior parte do professorado de EF tem uma jornada maior que 40 horas semanais, seja no trabalho em escolas, seja em outras atividades laborais fora do âmbito escolar. No estudo de Costa (2009), foi apontado que 50\% do professorado tem jornada maior que 40 horas; na dissertação de Baccin (2010), 66\% do professorado tem jornada superior a esse limite; nos estudos de Bermudes (2010) e Lemos (2011), 80\% dos docentes investigados têm jornada superior a 40 horas; Andrade (2011) apontou que a média de carga horária dos docentes é de 50 horas semanais; e, nos estudos de Sinott (2013) e Veiga (2013), 70\% têm jornada igual ou superior a 40 horas semanais.

De acordo com Andrade (2011, p. 75), “estes dados parecem refletir a situação atual da educação, onde o cenário de desvalorização profissional faz com que os professores aumentem sua carga horária de trabalho, inserindo-se em outros espaços de trabalho a fim de melhorar os seus vencimentos". Além da desvalorização salarial, a jornada excessiva de trabalho também implica desqualificação dos processos de ensino-aprendizagem, tal como aponta o estudo de Bermudes (2010, p. 103) sobre avaliação, em que "a intensa carga horária de trabalho docente não permite uma 'entrega' maior na efetivação das práticas avaliativas, ou seja, na forma de planejamento e registros pedagógicos".

Outro aspecto identificado como elemento de precarização das condições de trabalho diz respeito à remuneração do professorado nas redes de ensino. Costa (2009) identificou que $50 \%$ dos docentes de EF têm remuneração entre três e quatro salários mínimos; no estudo de Lemos (2011), identificou-se que $60 \%$ dos docentes recebem entre um a três salários mínimos; Sinott (2013) e Veiga (2013) apresentam o dado de que 65\% têm renda familiar menor que cinco salários mínimos. Tais estudos apontaram que, em decorrência da baixa remuneração, a qualidade do ensino é prejudicada, pois os docentes buscam outras formas de ampliação de sua renda, aumentando suas horas de trabalho, o que ocasiona desmotivação em relação ao trabalho docente. Andrade (2011, p 76-77) apresenta que "os sentimentos de insatisfação, que comprometem a motivação dos professores, estão relacionados com a baixa remuneração, com as suas condições de trabalho e com a falta de apoio por parte dos gestores".

Praticamente a totalidade das dissertações analisadas concluiu que há uma grande carência em relação à infraestrutura e a materiais para as aulas de EF nas escolas públicas. As principais conclusões a que chegaram as pesquisas foram: escolas sem condições para inclusão escolar (COSTA, 2009); as escolas necessitam de melhores condições materiais e de instalação (VARGAS, 2009); escola com turmas lotadas de estudantes, diminuição de professores, precária infraestrutura, poucos materiais para aulas de EF e com péssima qualidade (BACCIN, 2010); precárias condições de infraestrutura, materiais do esporte extraescolar e da disciplina regular de EF são diferenciados (ANDRADE, 2011); crescente insatisfação do professorado com as condições de trabalho (VEIGA, 2013). Sobre esse aspecto, um fragmento da dissertação de Lemos (2011, p 197) é bastante significativo sobre o que pensam os docentes de EF:

Tais reclamações advêm da pouca segurança que a escola oferece aos seus professores, alunos e funcionários, das precárias condições de trabalho quan- 
to à infraestrutura, praticamente sem espaço físico para o professor de educação física desenvolver suas aulas, o material de trabalho das escolas é muito escasso e ruim. Ainda sabemos que o professor de educação física da área escolar trabalha no sol, no frio e muitas vezes na neblina e não recebe insalubridade por conta disso.

Na dissertação de Andrade (2011), foi apresentado ainda outro fator bastante pertinente para a compreensão dos impactos que a precarização do trabalho docente ocasiona para o desenvolvimento das atividades escolares. De acordo com a pesquisa, os docentes que trabalham com esporte escolar buscam recursos privados para a aquisição de materiais esportivos e a realização de viagens para disputas de campeonatos escolares, assim como as horas destinadas às viagens e competições estudantis não são remuneradas. Uma das conclusões do estudo é que

A falta de condições físicas e materiais pode ser um elemento que contribui significativamente para o sentimento de insatisfação profissional. Embora o professor tenha consciência de que possa realizar um trabalho mais qualificado, estes elementos, por não estarem ao seu alcance, promovem o sentimento de acomodação e desinvestimento por parte dos professores (ANDRADE, 2011, p. 67).

A precarização do trabalho docente, nos estudos realizados no PPGEF/UFPel, indica que impacta negativamente a qualidade da educação, acarretando prejuízos para a formação dos estudantes e o crescente descontentamento dos docentes com as condições de trabalho.

\section{B) Formação inicial e continuada}

No que tange à formação profissional, as dissertações produzidas que relacionaram esse tema com o trabalho docente apontaram, de maneira geral, a fragilidade da formação inicial em cursos de Licenciatura em EF nas universidades e a carência de ações de formação continuada para o professorado da rede pública de ensino.

Dentre os aspectos problemáticos da formação inicial, destacamos algumas conclusões dos estudos: formação inicial frágil para o trabalho de inclusão de pessoas com deficiência (COSTA, 2009); não contempla orientações sobre o funcionamento e o exercício da gestão escolar (QUINTANA, 2010); formação inicial é limitada em relação à avaliação da aprendizagem na EF (BERMUDES, 2010); o currículo de graduação é esvaziado em relação a questões políticas e de gestão da educação (OST, 2012). Essas fragilidades da formação do professorado apresentam limitações para o desenvolvimento do trabalho docente na rede pública. Conforme os relatos dos docentes, eles sentem-se despreparados para exercer suas funções pedagógicas no momento em que ingressam na rede pública de ensino.

Um dos aspectos que influenciam no despreparo de docentes para atuação na escola, segundo os estudos de Both (2009) e Lemos (2011), é oriundo da fragmentação da formação em EF em dois cursos distintos - Licenciatura e Bacharelado -, que trouxe prejuízos para a formação do professorado de EF em todos os campos de atuação em virtude da fragmentação do conhecimento.

A dicotomia, ou seja, a fragmentação do curso de Educação Física foi um fator que os(as) egressos(as), em sua grande maioria, acreditam ser equivocada. A separação da formação entre licenciatura e bacharelado foi demasiadamente refutada. As consequências, segundo os(as) egressos(as), da dicotmia intensificou ainda mais a fragmentação do conhecimento da área (LEMOS, 2011, p. 261). 
A partir das críticas à fragmentação da formação indicada pelos sujeitos da sua pesquisa, Both (2009) estabelece uma relação entre a realidade da precarização da formação com os movimentos mais gerais do capital e da restruturação produtiva decorrente da atual crise sistêmica.

\begin{abstract}
A formação que vem sendo realizada nos cursos de graduação em Educação Física atende aos interesses do capital, pois ao invés do debate centrar-se no aspecto epistemológico, ou seja, colocar como centro da discussão o objeto central da Educação Física ser a docência, independente do local de atuação, e então ver como se poderia estruturar o currículo com vistas ao trabalhador da área compreender e trabalhar nos diferentes campos de atuação, o debate é realizado a partir da necessidade da formação de um trabalhador para atuar num dito novo mercado de trabalho, cindindo tanto o conhecimento a ser produzido e socializado, bem como dificultando uma compreensão sob a perspectiva da totalidade por parte dos trabalhadores da área (BOTH, 2009, p. 97).
\end{abstract}

Os aspectos apontados nas dissertações acerca da carência de ações de formação continuada nas redes municipal e estadual de Pelotas (RS) podem ser exemplificados pelas seguintes conclusões dos estudos: não há estímulo para a formação continuada (BACCIN, 2010); faltam oportunidades e incentivos para a formação continuada (ANDRADE, 2011); a realização de ações são manifestações sinuosas, dependentes da gestão municipal (OST, 2012); há uma dificuldade de realizar atividades de formação continuada por parte do professorado por conta dos baixos salários e da falta de tempo decorrente da excessiva jornada de trabalho (BOTH, 2009). Junto a essas dificuldades, em determinadas situações a busca por certificação em níveis superiores de ensino (especialização, mestrado e doutorado) corresponde à procura por melhores remunerações em vista das progressões no plano de carreira, tal como identificado no estudo de Costa (2009).

\title{
C) Políticas públicas
}

Em relação às políticas públicas, os principais aspectos apontados pelas dissertações são referentes a medidas efetivas para a implementação da inclusão de deficientes nas escolas (COSTA, 2009); a reversão das políticas meritocráticas e de avaliação institucional, que ferem a autonomia pedagógica das instituições (BOTH, 2009; BACCIN, 2010); a gestão antidemocrática (QUINTANA, 2010); e o não pagamento do piso salarial nacional nas redes estadual e municipal de Pelotas (RS) (BACCIN, 2010)

Outro aspecto presente nas dissertações se refere à ausência de políticas públicas relativas à formação continuada dos professores de EF e à necessidade de aproximar universidade e escola (ANDRADE, 2011). Além disso, as políticas de formação continuada não constituem um processo linear (OST, 2012).

Essas críticas apontadas, vinculadas às precárias condições de trabalho e de formação, dão conta de compreender que as políticas públicas partem de um projeto educacional voltado à lógica da mercantilização da educação, na medida em que se intensificam processos de precarização das escolas e de produtividade de docentes e estudantes sob um viés de gestão empresarial, na qual são exigidos melhorias de desempenho sem que as condições de qualidade do ensino sejam garantidas.

\section{D) Saúde docente}


Todas as dissertações analisadas para este estudo apontaram, de alguma maneira, a questão da insatisfação profissional ou a desmotivação para o trabalho decorrente da realidade do trabalho docente, seja por conta da baixa remuneração, da exaustiva jornada de trabalho e das precárias condições de infraestrutura, seja por conta do despreparo da formação inicial para o trabalho docente, dentre outros elementos elencados anteriormente. Dentre os textos submetidos à análise, três dissertações abordaram como tema central a questão da saúde docente, chegando à conclusão de que a maior parte do professorado apresenta alta exaustão emocional, despersonalização e baixa realização profissional (SILVA, 2010), sintomas da Síndrome de Burnout constatados nos estudos de Sinott (2013) e Veiga (2013).

Nesse sentido, é bastante elucidativa a passagem de Veiga $(2013$, p. 81):

Os professores demonstraram altos percentuais de insatisfação com relação à sua remuneração em todas as fases da carreira, sendo que a remuneração e a compensação, embora tenham surgido como o motivo mais citado de todas as categorias, vieram, na maioria dos casos, acompanhadas de outros dados relacionados especialmente a condições de trabalho, falta de perspectivas de crescimento profissional, além da dificuldade de equilibrar vida profissional e pessoal em função de carga horária elevada, aspectos claramente decorrentes do modo como o município e o estado tratam a educação e o ensino público.

Os elementos de precarização do trabalho docente identificados repercutem também na vida do professorado. A falta de perspectivas em relação à educação e à sua carreira, acompanhadas da exaustão decorrente do trabalho intenso, torna os docentes mais desmotivados e em uma constante busca por melhores condições de vida, seja na carreira docente, seja fora dela. A Síndrome de Burnout, presente no cotidiano docente, é um distúrbio psíquico de caráter depressivo, provocado pelo esgotamento físico e mental ligado à vida profissional.

\section{Considerações finais}

Com o objetivo de sistematizar a produção do conhecimento desenvolvida no PPGEF/UFPel sobre o trabalho docente da EF nas escolas públicas de Pelotas (RS), este estudo permitiu identificar os principais elementos presentes na realidade do trabalho do professorado da EF. Com base nas dissertações produzidas a partir de trabalhos de campo que levantaram dados empíricos junto ao professorado, foi possível estabelecer conexões entre a produção do conhecimento e a realidade concreta.

Ao compilarmos o conjunto de dissertações objeto desta investigação, foi possível identificar aspectos significativos em relação à produção do conhecimento em EF, especialmente o fato de que a maior parte $(58 \%)$ das dissertações defendidas no PPGEF/UFPel é oriunda da área de concentração MHES, cujas cujas produções são, em sua maioria, fundamentadas nas Ciências Sociais e Humanas da EF.

As categorias estabelecidas como resultados da análise apontaram que há uma crescente precarização da educação pública em função da falta de investimentos nas escolas e na carreira docente. A exaustiva jornada de trabalho, a baixa remuneração e a carência de infraestrutura e de material para as aulas de EF foram apontadas na totalidade das dissertações produzidas. Esses elementos, acompanhados da fragilidade da formação inicial e da carência de ações de formação continuada, bem como de políticas públicas insuficientes e do esgotamento profissional, apontam uma realidade do trabalho docente bastante preocupante para a qualidade do ensino e para a vida do professorado.

Embora se identifique que os docentes buscam, de diferentes formas, qualificar o seu trabalho, eles encontram dificuldades no tocante à estrutura da educação pública encontrada 
na realidade das escolas públicas. Tal fato aponta uma constante necessidade de enfrentar essa realidade junto às administrações para a garantia de uma educação pública de qualidade. Entendemos, por fim, que a produção do conhecimento tem um papel fundamental para a compreensão da realidade do trabalho docente como forma de instrumentalizar a categoria docente na explicação e nas ações que buscam modificar essa precária estrutura da escola pública, especialmente no que tange à EF.

\title{
THE PRODUCTION OF PPGEF/UFPEL ON THE REALITY OF TEACHING JOB IN PUBLIC SCHOOLS PELOTAS/RS/BRAZIL
}

\begin{abstract}
The present study aimed to systematize the knowledge production developed in the PPGEF/UFPel on the teaching work of Physical Education in public schools in Pelotas, RS (Brazil). After analysis of the totality of the productions dissertations were found. From the analysis of content we establish four categories: a) working conditions and infrastructure; B) initial and continuing training; C) public policies; D) teacher health. The studies pointed to a precariousness of public education and teaching career, exhaustive working hours, low remuneration, lack of infrastructure and materials for EF classes. It was also found the fragility of initial training, the lack of continuous training actions, insufficient public policies and Burnout Syndrome.

Keywords: Physical Education. Production of Knowledge. Public Education.

\section{LA PRODUCCIÓN DE CONOCIMIENTO EN PPGEF/UFPEL SOBRE LA REALIDAD DEL TRABAJO DE ENSEÑANZA EN LAS ESCUELAS PÚBLICAS PELOTAS/RS/BRASIL}

\begin{abstract}
Resumen
Este estudio tuvo como objetivo sistematizar la producción de conocimiento desarrollado en PPGEF/UFPel sobre el quehacer del profesorado de Educación Física en las escuelas públicas de Pelotas. Después de una búsqueda relacionada al total de las producciones fueron encontradas 14 disertaciones. A partir del análisis del contenido establecimos cuatro categorías: a) condiciones de trabajo e infraestructura; b) formación inicial y continua; c) políticas públicas; d) salud docente. Los estudios mostraron la precarización de la educación pública y de la profesión docente, jornadas de trabajo exhaustivas, bajos sueldos, falta de infraestructura y de materiales para las clases de educación física. Se constató incluso, la fragilidad de la formación inicial y la falta de formación continuada, políticas públicas insuficientes y agotamiento profesional.
\end{abstract}

Palabras clave: Educación Física. Producción de Conocimiento. Educación Pública.

\section{Referências}

ANDRADE, D. M. Caracterização dos professores de Educação Física que trabalham com esporte extraclasse: motivações, trajetórias, saberes e identidades. 2011. 87 f. Dissertação (Mestrado em Educação Física) - Programa de Pós-Graduação em Educação Física, Pelotas, 2011. 
BACCIN, E. V. C. Educação Física escolar: implicações das políticas educacionais na organização do trabalho pedagógico. 2010. 137 f. Dissertação (Mestrado em Educação Física) Programa de Pós-Graduação em Educação Física, UFPel, Pelotas, 2010.

BARDIN, Lawrence. Análise de conteúdo. Lisboa: Edições 70, LDA, 2009.

BERMUDES, R. Construção dos saberes sobre as práticas avaliativas dos professores de Educação Física. 2010. 119 f. Dissertação (Mestrado em Educação Física) - Programa de Pós-Graduação em Educação Física, UFPel, Pelotas, 2010.

BOTH, V. J. Mudanças no mundo do trabalho e suas mediações na Educação Física. 2009. 121 f. Dissertação (Mestrado em Educação Física) - Programa de Pós-Graduação em Educação Física, UFPel, Pelotas, 2009.

BRASIL. Constituição de. Lei no ${ }^{\circ} 11.738$, de 16 de julho de 2008. Regulamenta a alínea "e" do inciso III do caput do art. 60 do Ato das Disposições Constitucionais Transitórias, para instituir o piso salarial profissional nacional para os profissionais do magistério público da educação básica. Diário Oficial da União, Brasília, DF, v. 17.

COSTA, F. R. B. Formação e desenvolvimento profissional em Educação Física dilemas e desafios na educação inclusiva. 2009. 101 f. Dissertação (Mestrado em Educação Física) Programa de Pós-Graduação em Educação Física, UFPel, Pelotas, 2009.

FILIPPINI, I.; FRIZZO, G. As relações entre o singular e o geral na precarização das condições de trabalho da Educação Física na escola. Revista Kinesis, Santa Maria, v. 31, n. 1, p. 57-71, jan/jun 2013.

FRIZZO, G. A Produção do conhecimento da Educação Física no Programa de PósGraduação em Ciências do Movimento Humano da UFRGS. Pensar a Prática, Goiânia, v. 13, n. 3, p. 1-16, set./dez. 2010.

IVO, A.; HYPÓLITO, A. Política gerencial em educação: efeitos sobre o trabalho docente. Currículo sem Fronteiras, v. 15, n. 2, p. 365-379, maio/ago. 2015.

JOB, I. Educação Física no PPGCMH/UFRGS: uma visão a partir da análise de citações e perfil dos pesquisadores. 2006. Dissertação (Mestrado em Ciência da Informação) - UFMG, Belo Horizonte, 2006.

LEMOS, L. M. Formação e trabalho do(a) professor(a) de Educação Física na formação social capitalista. 2011, 289 f. Dissertação (Mestrado em Educação Física) - Programa de Pós-Graduação em Educação Física, UFPel, Pelotas, 2011.

MOLINA NETO, V. Pós-Graduação em Educação Física: um olhar sobre o Programa da ESEFUFRGS. Revista Brasileira de Ciências do Esporte. Florianópolis, v. 20, p. 410, 1999.

MOLINA NETO, V.; WITTIZORECKI, E. S. O trabalho docente dos professores de Educação Física na rede municipal de ensino de Porto Alegre. Revista Movimento, Porto Alegre, v. 11, n. 1, p.47-70, jan./abr. de 2005. 
OST, M. A. Formação continuada em Educação Física: um estudo sobre as propostas da Secretaria de Educação e Desporto da Prefeitura Municipal de Pelotas-RS. 2012, 113 f. Dissertação (Mestrado em Educação Física) - Programa de Pós-Graduação em Educação Física, UFPel, Pelotas, 2012.

QUINTANA, J. C. O professor de Educação Física na direção da escola pública estadual. 2010, 124 f. Dissertação (Mestrado em Educação Física) - Programa de Pós-Graduação em Educação Física, UFPel, Pelotas, 2010.

SANTINI, J. Síndrome do esgotamento profissional: revisão bibliográfica. Revista Movimento, Porto Alegre, v. 10, n. 1, p. 183-209, jan./abr. de 2004.

SILVA, M. S. S. J. Síndrome de Burnout em professores de Educação Física das escolas estaduais do ensino médio da cidade de Pelotas/RS. 2010, 87 f. Dissertação (Mestrado em Educação Física) - Programa de Pós-Graduação em Educação Física, UFPel, Pelotas, 2010.

SINOTT et al. Síndrome de Burnout: um estudo com professores de Educação Física. Revista Movimento, Porto Alegre, v. 20, n. 2, p. 519-539, abr./jun. 2014.

SINOTT, E. Síndrome de Burnout: um estudo com professores de Educação Física das escolas municipais de Pelotas. 2013. 134 f. Dissertação (Mestrado em Educação Física) - Programa de Pós-Graduação em Educação Física, UFPel, Pelotas, 2013.

SOUZA, M. S.; RIBAS, J. M.; CALHEIROS, V. Conhecimento em Educação Física no movimento das mudanças do mundo do trabalho. Santa Maria: Editora UFSM, 2015.

VARGAS, J. E. N. Educação Física no ensino médio noturno na região sul do Rio Grande do Sul: realidades e possibilidade. 2009. 106 f. Dissertação (Mestrado em Educação Física) - Programa de Pós-Graduação em Educação Física, UFPel, Pelotas, 2009.

VEIGA, R. F. Qualidade de vida no trabalho dos professores de educação física da rede municipal de ensino de Pelotas. 2013. 119 f. Dissertação (Mestrado em Educação Física) Programa de Pós-Graduação em Educação Física, UFPel, Pelotas, 2013.

Recebido em: 26/01/2017

Revisado em: 03/04/2017

Aprovado em: 05/04/2017

Endereço para correspondência:

ivanbremmoliveira@gmail.com

Ivan Bremm De Oliveira

Universidade Federal de Pelotas

R. Gomes Carneiro, 1 - Centro, Pelotas - RS, 96010-610 